\title{
A Review of Flywheel Energy Storage System Technologies and Their Applications
}

\author{
Mustafa E. Amiryar* and Keith R. Pullen * \\ School of Mathematics, Computer Science and Engineering, University of London, London EC1V 0HB, UK \\ * Correspondence: mustafa.amiryar.2@city.ac.uk (M.E.A); k.pullen@city.ac.uk (K.R.P.); \\ Tel.: +44-(0)20-7040-3475 (K.R.P.)
}

Academic Editor: Frede Blaabjerg

Received: 10 December 2016; Accepted: 9 March 2017; Published: 16 March 2017

\begin{abstract}
Energy storage systems (ESS) provide a means for improving the efficiency of electrical systems when there are imbalances between supply and demand. Additionally, they are a key element for improving the stability and quality of electrical networks. They add flexibility into the electrical system by mitigating the supply intermittency, recently made worse by an increased penetration of renewable generation. One energy storage technology now arousing great interest is the flywheel energy storage systems (FESS), since this technology can offer many advantages as an energy storage solution over the alternatives. Flywheels have attributes of a high cycle life, long operational life, high round-trip efficiency, high power density, low environmental impact, and can store megajoule (MJ) levels of energy with no upper limit when configured in banks. This paper presents a critical review of FESS in regards to its main components and applications, an approach not captured in earlier reviews. Additionally, earlier reviews do not include the most recent literature in this fast-moving field. A description of the flywheel structure and its main components is provided, and different types of electric machines, power electronics converter topologies, and bearing systems for use in flywheel storage systems are discussed. The main applications of FESS are explained and commercially available flywheel prototypes for each application are described. The paper concludes with recommendations for future research.
\end{abstract}

Keywords: energy storage systems (ESS); flywheel energy storage systems (FESS); power electronics converters; power quality improvement

\section{Introduction}

Energy storage systems (ESS) can be used to balance electrical energy supply and demand. The process involves converting and storing electrical energy from an available source into another form of energy, which can be converted back into electrical energy when needed. The forms of energy storage conversion can be chemical, mechanical, thermal, or magnetic [1,2]. ESS enable electricity to be produced when it is needed and stored when the generation exceeds the demand. Storage is beneficial when there is a low demand, low generation cost, or when the available energy sources are intermittent. At the same time, stored energy can be consumed at times of high demand, high generation cost, or when no alternative generation is available [1-4].

Energy demand continues to increase, as demanded by the households and industries with high growth rates in BRIC and developing countries. This has led to increases in energy prices and traditional energy generation methods are less able to adapt, exacerbating the issues due to market deregulation, power quality problems, and pressures to limit carbon dioxide emissions [2,3]. Renewable energy sources (RES) and potential distributed generation (DG) are considered as supplements or replacements for traditional generation methods [3]; however, there are major challenges associated with energy supply coming from renewables, due to their intermittent nature 
across a range of timescales [4]. At a time when RES are supplying energy, there may be low demand, but when the energy is demanded, it may exceed RES energy production [3]. Also, there are monthly, seasonal, and annual fluctuations in RES supply, as their availability is always subject to weather conditions. On the other hand, the energy demand differs from time to time, which does not necessarily match the intermittences of RES, thus creating reliability problems [3,4]. Therefore, ESS are a vital necessity to aggregate traditional generating plants in order to meet an excessive demand, and supplement intermittent RES for their integration into the electrical network [5].

As a counterpart to today's electrical network, there is a high demand for reliable, cost-effective, long lasting, and environmentally sound energy storage systems to support a variety of energy storage applications. With advances in materials technology, bearings, and power electronics, the technology of flywheels for energy storage has significantly developed [6,7]. Flywheels with the main attributes of high energy efficiency, and high power and energy density, compete with other storage technologies in electrical energy storage applications, as well as in transportation, military services, and space satellites [8]. With storage capabilities of up to $500 \mathrm{MJ}$ and power ranges from $\mathrm{kW}$ to $\mathrm{GW}$, they perform a variety of important energy storage applications in a power system $[8,9]$. The most common applications of flywheels in electrical energy storage are for uninterruptible power supplies (UPS) and power quality improvement [10-12]. For these applications, the electrochemical battery is highly mismatched and suffers from an insufficient cycle life, since the number of cycles per day is usually too high [13]. The authors note that this is not necessarily true for some UPS with highly reliable grids, so storage is seldom called upon. Particularly for power quality improvement, electrical disturbances are frequent but short, with the vast majority of them lasting for less than $5 \mathrm{~s}$. Such disturbances are effectively managed by flywheels and offer an improvement over batteries considering the instantaneous response time and longer life cycle of the former. Even with one cycle a day, an electrochemical battery is unlikely to last for even 10 years under these circumstances (3650 cycles). This can only be achieved if the depth of discharge is kept low and the battery is carefully managed, both electrically and thermally. It also requires specifying an energy storage capacity two to five times the required capacity, to reduce the depth of discharge, thus leading to a higher cost. Supercapacitors have been tested for these types of applications; however, with more or less the same capital cost as flywheels [1], their operational lifetime is relatively low (reaching up to 12 years) [3]. To make more use of such a system and minimise its capacity in order to reduce the cost, it is more useful for the storage system to be used many times a day, to allow for the time shifting of demand and to feed into the grid at times of high demand. Interest in this new paradigm of how energy is used will be greatly enhanced once Time of Use (ToU) tariffs are in place.

A number of reviews of flywheel storage systems have been presented by several papers in the literature. A comparison of energy storage technologies is made in [14], where a numerical and graphical review demonstrates the improvements and problems associated with FESS. A comparative analysis of energy storage technologies for high power applications is carried out in [15] and a survey of FESS for power system applications is provided in [16]. The control of high speed FESS in space applications is discussed in [17]. FESS is briefly reviewed in [18] and an overview of some previous projects is presented in [9]; however, such sources offer a scarcity of information. The authors of [19] focus on the developments of motor-generator (MG) for FESS, where the common electrical machines used with flywheels, along with their control, is reported in [20]. A review and simulation of FESS for an isolated wind power system is presented in [10]. This review takes a different approach from earlier work and particularly picks up on very recent literature in what is a rapidly developing subject.

This paper focuses on the description and applications of FESS, providing an overview of some commercial projects for each application. Many of the above papers have provided reviews of FESS, but what is missing in the literature is a comprehensive review of FESS with a description of the applications which are commercially available. Following the introduction, a description of FESS is presented. The main components of FESS, including the rotor, electrical machine, bearings, and flywheel containment are discussed in detail in Section 2. A flywheel's main characteristics 
are stated in Section 3 and its applications are described in Section 4 . The paper concludes with recommendations for future research in Section 5.

\section{Description of Flywheel Energy Storage System}

\subsection{Background}

The flywheel as a means of energy storage has existed for thousands of years as one of the earliest mechanical energy storage systems. For example, the potter's wheel was used as a rotatory object using the flywheel effect to maintain its energy under its own inertia [21]. Flywheel applications were performed by similar rotary objects, such as the water wheel, lathe, hand mills, and other rotary objects operated by people and animals. These spinning wheels from the middle ages do not differ from those used in the 19th or even 20th centuries. In the 18th century, the two major developments were metals replacing wood in machine constructions and the use of flywheels in steam engines. Developments in cast iron and the production of iron resulted in the production of flywheels in one complete piece, with greater moment of inertia for the same space [21]. The word 'flywheel' appeared at the beginning of the industrial revolution (namely in 1784). At the time, flywheels were used on steam engine boats and trains and as energy accumulators in factories [22]. In the middle of 19th century, as a result of the developments in cast iron and cast steel, very large flywheels with curved spokes were built. The first three-wheeled vehicle was built by Benz in 1885 and can be named as an example [21]. Over time, several shapes and designs have been implemented, but major developments came in the early 20th century, when rotor shapes and rotational stresses were thoroughly analysed, and flywheels were considered as potential energy storage systems [23]. An early example of a flywheel system used in transport was the Gyrobus, powered by a $1500 \mathrm{~kg}$ flywheel, produced in Switzerland during the 1950s [24]. In the 1960s and 1970s, FESS were proposed for electric vehicles, stationary power back up, and space missions $[9,10]$. In the following years, fibre composite rotors were built and tested. In the 1980s, relatively low-speed magnetic bearings started to appear [25].

Despite major developments during their early stages, the utilization of flywheels has not been significant and has declined with the development of the electric grid. However, due to the recent improvements in materials, magnetic bearings, power electronics, and the introduction of high speed electric machines, FESS have been established as a solid option for energy storage applications [7-9,26,27].

A flywheel stores energy that is based on the rotating mass principle. It is a mechanical storage device which emulates the storage of electrical energy by converting it to mechanical energy. The energy in a flywheel is stored in the form of rotational kinetic energy. The input energy to the FESS is usually drawn from an electrical source coming from the grid or any other source of electrical energy. The flywheel speeds up as it stores energy and slows down when it is discharging, to deliver the accumulated energy. The rotating flywheel is driven by an electrical motor-generator (MG) performing the interchange of electrical energy to mechanical energy, and vice versa $[28,29]$. The flywheel and MG are coaxially connected, indicating that controlling the MG enables control of the flywheel [30-33].

\subsection{Structure and Components of FESS}

FESS consist of a spinning rotor, MG, bearings, a power electronics interface, and containment or housing, which are discussed in detail in the following subsections. A typical flywheel system suitable for ground-based power is schematically shown in Figure 1. 


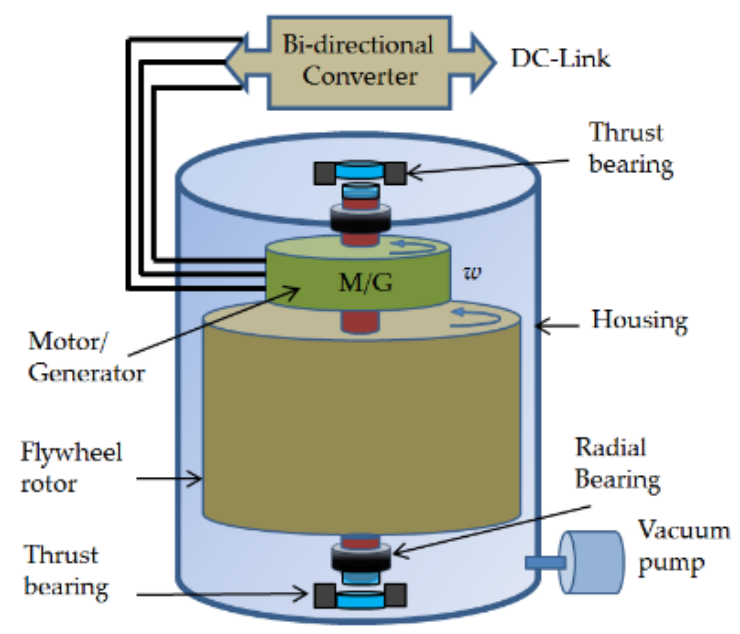

Figure 1. Structure and components of a flywheel.

\subsubsection{Flywheel Rotor}

The stored energy in a flywheel is determined by the rotor shape and material. It is linearly proportional to the moment of inertia and the square of its angular velocity, as shown in Equation (1) [27,34]:

$$
E=\frac{1}{2} I \omega^{2}
$$

where $E$ is the stored kinetic energy, $I$ is the moment of inertia, and $\omega$ is the angular velocity. The useful energy of a flywheel within a speed range of minimum speed $\left(\omega_{\min }\right)$ and maximum speed $\left(\omega_{\max }\right)$ can be obtained by:

$$
E=\frac{1}{2} I\left(\omega_{\max }{ }^{2}-\omega_{\min }{ }^{2}\right)=\frac{1}{2} I \omega_{\max }^{2}\left(1-\frac{\omega_{\min ^{2}}}{\omega_{\max ^{2}}}\right)
$$

Typically, an electrically driven flywheel normally operates between $\left(\omega_{\min }\right)$ and $\left(\omega_{\max }\right)$, to avoid too great a voltage variation and to limit the maximum MG torque for a given power rating. The moment of inertia is a function of the mass of the rotor and the rotor shape factor. Flywheels are often built as solid or hollow cylinders, ranging from short and disc-type, to long and drum-type [28,35]. For a solid cylinder or disc-type flywheel, the moment of inertia is given by:

$$
I=\frac{1}{2} m r^{2}
$$

where $m$ is the rotor mass and $r$ is the outer radius. For a hollow cylinder flywheel of outer radius $b$ and inner radius $a$, as shown in Figure 2, the moment of inertia is:

$$
I=\frac{1}{2} m\left(b^{2}-a^{2}\right)
$$

For a flywheel with length $h$ and mass density $\rho$, the moment of inertia is determined by:

$$
I=\frac{1}{2} \pi \rho h\left(b^{4}-a^{4}\right)
$$

Thus:

$$
E=\frac{1}{4} \pi \rho h \omega^{2}\left(b^{4}-a^{4}\right)
$$




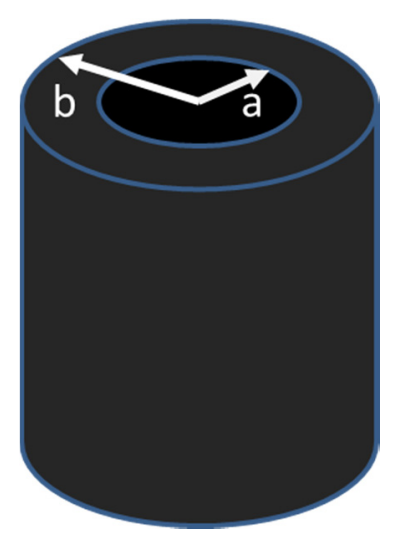

Figure 2. Hollow cylinder flywheel.

The maximum speed limit at which a flywheel may operate is determined by the strength of the rotor material, called tensile strength $\sigma[18,23]$. A suitable safety margin must be maintained, to keep the stress experienced by the rotor below the strength of the rotor material. The maximum stress of a thin rotating ring is given by:

$$
\sigma_{\max }=\rho r^{2} \omega^{2}
$$

where $\sigma$ is the maximum stress and $\rho$ is the density of the flywheel material. More complex equations are available for different rotor geometries, but the maximum stress is always proportional to $\rho$, and the square of peripheral speed, equal to $r \omega$. The effect of rotor geometries can be accommodated by introducing a shape factor $K$. The maximum specific energy and energy density are then given by:

$$
\begin{aligned}
& \frac{E}{m}=K \frac{\sigma_{\max }}{\rho}[\mathrm{J} / \mathrm{kg}] \\
& \frac{E}{V}=K \sigma_{\max }\left[\mathrm{J} / \mathrm{m}^{3}\right]
\end{aligned}
$$

Equations (8) and (9) indicate that the specific energy (energy per mass unit) and energy density (energy per volume unit) of the flywheel are dependent on its shape, expressed as shape factor $K$. The shape of a flywheel is an important factor for determining the flywheel speed limit, and hence, the maximum energy that can be stored. The shape factor $K$ is a measurement of flywheel material utilisation [18]. Figure 3 shows the values of $K$ for the most common types of flywheel geometries.

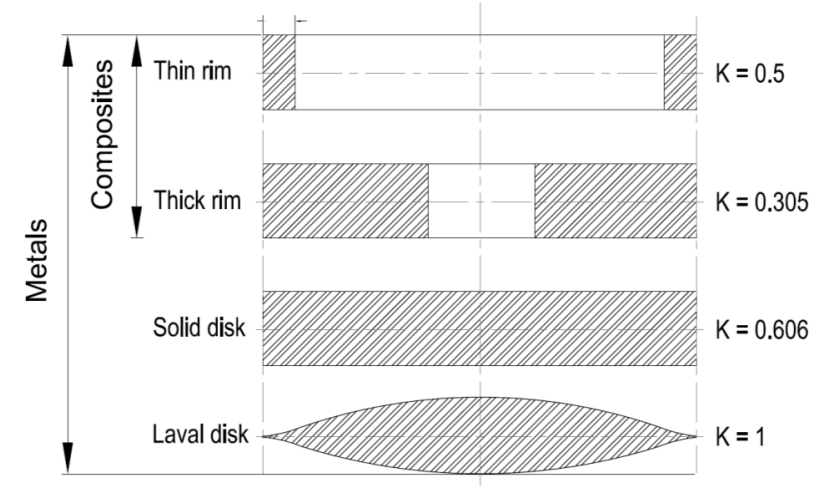

Figure 3. Different flywheel cross sections [18].

According to Equation (1), the stored energy of a flywheel can be optimised by either increasing the spinning speed $(\omega)$ or increasing the moment of inertia $(I)$. This allows two choices for FESS: low 
speed FESS (typically up to 10,000 rpm) and high speed FESS (up to 100,000 rpm) [18,23]. Low speed flywheels are usually made of heavier metallic material and are supported by either mechanical or magnetic bearings. High speed flywheels generally use lighter but strong composite materials and typically require magnetic bearings. The price of high speed flywheels can be up to five times higher than the cost of low speed flywheels, according to $[18,23]$. The authors note that the cost of a flywheel system is governed by the design of the whole system, not the rotor, although this core element may dictate the design of the other elements in the system, hence the total cost. A new class of intermediate speed flywheels, benefiting from the low cost of steel materials but a sufficiently high energy density, is also being developed, based on the use of laminated steel. This has the potential to offer low cost, but also compact, options [36].

\subsubsection{Electric Machine}

As explained previously, the electrical machine or integrated MG is coupled to the flywheel, to enable the energy conversion and charging process of the flywheel. The machine, acting as a motor, charges the flywheel by accelerating it and drawing electrical energy from the source. The stored energy on the flywheel is extracted by the same machine, acting as a generator, and hence, the flywheel is slowed down during discharge. Common electrical machines used in FESS are the induction machine (IM), permanent magnet machine (PM), and variable reluctant machine (VRM) [18,23].

An IM is used for high power applications due to its ruggedness, higher torque, and low cost [18]. The speed limitations, complex control, and higher maintenance requirements are the main problems with IMs [16]. The squirrel cage type can be a less expensive option for slow response applications [20]. A doubly fed induction machine (DFIM) has recently been used in FESS applications, due to its flexible control and lower power conversion rating, allowing mitigated power electronics sizing [16,20]. An IM is widely used in wind turbine applications to enable the power smoothing of wind generation systems $[16,20]$.

A VRM is very robust, and has low idling losses and a wide speed range. It has a simpler control mechanism than IMs, when it comes to high speed operations [16]. On the downside, it has a low power factor and low power density, as well as high torque ripples [16]. Both switched reluctance and synchronous reluctance types are applied in high speed FESS applications [20].

A PM is the most commonly used machine for FESS because of its higher efficiency, high power density, and low rotor losses [18]. It is widely used in high speed applications due to the speed limitations of IMs, and the torque ripple, vibration, and noise of VRMs. The problem with a PM is its idling losses due to stator eddy current losses, its high price, and its low tensile strength [18]. A brushless dc machine (BLDCM), permanent magnet synchronous machine (PMSM), and Halbach array machine (HAM), are the main types of PM machines used in FESS applications [20]. A comparison between IMs, VRMs, and PMs is presented in Table 1. Regarding the quantification of specific power, the authors in [18] appear to have misreported the published values. In our experience, depending on the rotor speed, the specific power of an IM and VRM would be around half of that of the PM, and not the large difference shown in [18]. In fact, further analysis of the original literature reports that the specific power density of PM synchronous machines is approximately $1.2 \mathrm{~kW} / \mathrm{kg}$ [37].

Table 1. Comparison of electrical machines suitable for use in FESS [18,19].

\begin{tabular}{clll}
\hline Machine & \multicolumn{1}{c}{ Asynchronous } & \multicolumn{1}{c}{ Variable Reluctance } & \multicolumn{1}{c}{ Permanent Magnet Synchronous } \\
\hline Power & High & Medium and low & Medium and low \\
\hline $\begin{array}{c}\text { Specific power } \\
\text { Rotor losses }\end{array}$ & $\begin{array}{l}\text { Medium }(\sim 0.7 \mathrm{~kW} / \mathrm{kg}) \\
\text { Copper and iron }\end{array}$ & $\begin{array}{l}\text { Medium }(\sim 0.7 \mathrm{~kW} / \mathrm{kg}) \\
\text { Iron due to slots }\end{array}$ & $\begin{array}{l}\text { High }(\sim 1.2 \mathrm{~kW} / \mathrm{kg}) \\
\text { Very low }\end{array}$ \\
\hline Spinning losses & Removable by annulling flux & Removable by annulling flux & Non-removable, static flux \\
\hline Efficiency & High $(93.4 \%)$ & High $(93 \%)$ & Very high $(95.5 \%)$ \\
\hline Control & Vector control & $\begin{array}{l}\text { Synchronous: Vector Control. } \\
\text { Switched: DSP }\end{array}$ & $\begin{array}{l}\text { Sinusoidal: Vector control. } \\
\text { Trapezoidal: DSP }\end{array}$ \\
\hline
\end{tabular}


Table 1. Cont.

\begin{tabular}{|c|c|c|c|}
\hline Machine & Asynchronous & Variable Reluctance & Permanent Magnet Synchronous \\
\hline Size & $1.8 \mathrm{~L} / \mathrm{kW}$ & $2.6 \mathrm{~L} / \mathrm{kW}$ & $2.3 \mathrm{~L} / \mathrm{kW}$ \\
\hline Tensile strength & Medium & Medium & Low \\
\hline Torque ripple & Medium $(7.3 \%)$ & High $(24 \%)$ & Medium $(10 \%)$ \\
\hline Maximum/base speed & Medium $(>3)$ & High $(>4)$ & Low $(<2)$ \\
\hline Demagnetization & No & No & Yes \\
\hline Cost & Low $(22 € / \mathrm{kW})$ & Low $(24 € / \mathrm{kW})$ & Low $(38 € / \mathrm{kW})$ \\
\hline \multirow{10}{*}{ Advantages } & Low cost & $\begin{array}{l}\text { Robustness of } \\
\text { temperature overheat }\end{array}$ & Low loss, high efficiency \\
\hline & Simple manufacture & Overcurrent capability & High power density \\
\hline & Technology-matured & $\begin{array}{l}\text { Excitation coil can repeat } \\
\text { adjustment }\end{array}$ & High load density \\
\hline & Adjustable power factor & Lower loss at starting torque & High torque density \\
\hline & No demagnetization & Easy to dissipate heat & Small volume, light quality \\
\hline & High energy storage & Lower loss, higher efficiency & low rotor resistance loss \\
\hline & No running loss & High power density & No field winding loss \\
\hline & & & Flexible shape and size \\
\hline & & & Simple control mode \\
\hline & & & High reliability \\
\hline \multirow{6}{*}{ Disadvantages } & High slip ratio of rotor & Complex structure & poor robustness of temperature \\
\hline & Limited speed & Difficult to manufacture & Demagnetisation \\
\hline & Larger volume & Low power factor & High cost \\
\hline & Low power to quality ratio & $\begin{array}{l}\text { Torque ripple, } \\
\text { vibration and noise }\end{array}$ & Materials fragile \\
\hline & High losses, low efficiency & More outlet from machine & Difficult air gap flux- \\
\hline & & Difficult to regulate speed & field adjustment \\
\hline
\end{tabular}

To take advantage of both PMs and VRMs, hybrid PM reluctance machines have recently been developed. Other unconventional machine types for FESS are presented in [20] and the latest developments of MG for FESS are discussed in [19].

\subsubsection{Power Electronics}

The energy conversion in a FESS is accomplished by the electrical machine and a bi-directional power converter. The power electronic converter topologies that can be used for FESS applications are $\mathrm{DC}-\mathrm{AC}, \mathrm{AC}-\mathrm{AC}$, and AC-DC-AC, or a combination of these. The switching devices of the power converters are selected, based on their operational characteristics and application. These include a bipolar junction transistor (BJT), metal oxide semiconductor field effect transistor (MOSFET), insulated gate bipolar transistor (IGBT), and thyristor (SCR, GTO, MCT) [38]. The commonly used switches are a silicon controlled rectifier (SCR), gate turn off thyristor (GTO), and IGBT. SCR and GTO have been traditionally used for variable frequency power converters. However, IGBT has been greatly adopted in recent years, due to its higher power capability and higher switching frequencies [9].

The widely used configuration of power converters in FESS is the back-to-back (BTB) or AC-DC-AC configuration, connected to a DC link capacitor. The converters in the BTB topology are three-phase bridged semiconductor switches, often controlled by the pulse width modulation (PWM) technique [18]. The PWM uses rectangular pulses and modulates the width of these pulses to produce a variable waveform. The pulses are applied to the power electronics converter to produce a sinusoidal AC current from a DC input $[9,39]$. The grid side converter maintains the DC link voltage, where the machine side converter is used to control the operation of the MG and the flywheel.

A DC to AC converter, usually known as an inverter, produces an AC output of a desired magnitude and frequency from a fixed or variable DC input. Variable output waveforms are achieved by either varying the DC input or adjusting the gain of the inverter [40]. The widely used industrial 
applications of inverters for FESS are variable-speed ac motor drives, renewable energy, transportation, and uninterruptible power supplies (UPS) [40,41]. In wind power applications, an inverter is used to connect the FESS directly to the grid or to the DC link of the wind generator [42,43]. In high power and high voltage applications, the two level DC-AC inverters are limited to operating at a high frequency, due to switching losses and device rating constraints [44]. Multilevel inverters, with an additional DC link capacitor, can be used to generate higher voltages with a less transient $\mathrm{d} v / \mathrm{d} t$ and reduced THD [45]. The common multilevel converter topologies in industry are diode-clamped converters or neutral-point-clamped (NPC) converters, cascaded H-bridge (CHB) converters, and flying capacitor (FC) converters. A three-level twelve-pulse NPC converter topology for FESS is proposed in [46]. Two NPC converters are connected in BTB combination to connect the FESS to the PCC between the electrical grid and wind generation.

An AC to AC or matrix converter (MC) is an array of nine bidirectional switches arranged in a way to allow the connection of any of the output phases of the converter to any of the input phases. MCs are used to modify the amplitude, frequency, and phases of the waveforms between the two asynchronous ac systems [44]. During its early stages, the AC-AC power converter was termed a Forced Commutated Cycloconverter, as it mainly relied on forced commutated thyristors [45]. These converters became a viable alternative to BTB converters after the emergence of BJTs. A comparison of MCs and BTB converters is presented in [47]. MCs are compact in size and have a lower weight, since there are no large capacitors or inductors required for energy storage. However, the lack of an energy storing capacitor limits their maximum voltage transfer ratio to $86 \%$. This limit can be exceeded, but with the cost of unwanted low frequency components in the input and output waveforms [45]. AC-AC converters are used with FESS in dynamic voltage restorer applications to mitigate voltage sags [48,49]. The choice of the matrix converter improves the reliability of the system and increases the power density [48].

A cascaded DC-DC and DC-AC converter configuration can also be used for FESS applications connected to a DC microgrid. A three-phase full bridge circuit in series with a bidirectional Buck-boost converter is proposed in [50]. This combination will be used in more applications with the emergence of DC MG in the future.

In cases where the discharging speed of the FESS is low, a DC-DC boost converter is connected at the DC link between the BTB converters, to regulate the output voltage. The boost converter can be bypassed by a switch during the charging [51]. In [52], a Z-source inverter topology is used as an alternative to a boost converter. In this configuration, inverter output waveform distortion is reduced and the reliability of the system is greatly improved, because of the short circuit which can exist across any phase leg of the inverter.

A higher switching frequency for the inverter and rectifier reduces current ripples and increases control bandwidth, but switching losses will be increased. In addition, fast switching of the power converter reduces higher order harmonics to produce an improved sinewave. Harmonics can be further reduced by the introduction of AC filters on the converter AC side. Filters can reduce current ripples, winding deterioration, and losses [53,54].

\subsubsection{Bearings}

Bearings are required to keep the rotor in place with very low friction, yet provide a support mechanism for the flywheel [3]. The bearing system can be mechanical or magnetic, depending on the weight, lifecycle life, and lower losses [7]. Gas bearings cannot be used due to the vacuum within the enclosure. Traditionally mechanical ball bearings have been used, but these have a higher friction compared to magnetic bearings and also require higher maintenance as a result of lubricant deterioration [7]. These difficulties may be mitigated by using a hybrid system of magnetic and mechanical bearings. A magnetic bearing has no friction losses and does not require any lubrication but, if active, requires power to energize it. It stabilizes the flywheel by supporting its weight using permanent magnets [9]. Permanent (passive) magnetic bearings (PMB), active magnetic bearings 
(AMB), and superconducting magnetic bearings (SMB) are the main types of magnetic bearing systems [16]. A PMB has high stiffness, low cost, and low losses, due to lack of a current. However, it has limitations in providing stability and is usually considered as an auxiliary bearing system [16,18]. An AMB is operated by the magnetic field produced from current carrying coils controlling the rotor position. It positions the rotor through a feedback system by applying variable forces which are determined based on the deviation of the rotor position, due to external forces. An AMB has a high cost, a complicated control system, and consumes energy to operate, which in turn, adds to system losses [16]. FESS standby loss is affected by the AMB mass. As a result, increasing the rotational speed and AMB mass add to the AMB iron and copper loss [35]. To ensure a good efficiency of the overall system, a compromise between speed and losses has to be made. An SMB provides a high speed, frictionless, long life, compact, and stable operation. It is the best magnetic bearing for a high speed operation as it can stabilize the flywheel without electricity or a positioning system, according to $[9,16]$. However, an SMB requires a cryogenic cooling system as it operates at a very low temperature; but recently, it has been improved by using high temperature superconductors (HTS). The main drawback of an SMB system is its very high cost $[7,9,16]$. The parasitic losses of mechanical bearings are about $5 \%$ of the total storage capacity per hour unless hybrid systems are used. This factor is about $1 \%$ for electromagnetic bearings [14] and can be further lowered to $0.1 \%$ by using HTS bearings [55]. The use of hybrid bearings will reduce the losses and complexity of the control system and also provide a stable and cost effective solution [56]. A compact flywheel energy storage system assisted by hybrid mechanical-magnetic bearings is proposed in [57]. The magnetic levitation in the vertical orientation is maintained by the magnetic bearing, while the translational and rotational levitation is assisted by mechanical bearing. In [58], a combination of SMB and PMB have been analysed to reduce the cost of the cooling system. The position of the flywheel rotor is controlled by the PMB and the SMB is mainly used to suppress the rotor vibrations. However, the capability of PMB in restraining the system during high speeds still remains in question.

\subsubsection{Housing}

The housing has two purposes: to provide an environment for low gas drag and for the containment of the rotor in the event of a failure. The aerodynamic drag loss in an FESS increases with the cube of the rotational speed, if the system is operated in atmospheric pressure [23]. These losses are reduced by mounting the flywheel in a vacuum enclosure to improve the system performance and safety. The housing or enclosure is the stationary part of the flywheel and is usually made of a thick steel or other high strength material, such as composites. The container holds the rotor in a vacuum to control rotor aerodynamic drag losses by maintaining the low pressure inside the device, thus withstanding failures as a result of any possible rotor failures [28,29,59]. Operating the system in such a low pressure requires a vacuum pump and an efficient cooling system to handle the heat generated from MG and some other parts of FESS [23]. When the power into and out of the flywheel is via an electric machine, there are no rotary seals, so leakage can be very small. This means that the vacuum pump does not need to operate frequently, or can be eliminated with a sufficient sealing of the housing. The operation of the vacuum pump depends on the rotor type. Composite rotors have a very high tip speed requiring lower (harder) vacuum pressures and outgas, due to the nature of the polymer resin matrix materials in contrast to steel. An alternative approach [23] is to use a gas mixture of helium and air, which reduces both the aerodynamic drag loss and the system cooling requirements.

In the event of rotor failure, composite rotors tend to break into numerous small fragments and its energy is dissipated by friction as the fragments rotate inside the casing. As this happens, pressure is built up inside the casing and the end plates of the casing. If air enters during failure, then a much stronger dust type explosion must also be contained, leading to the need for stronger containment. Single piece steel rotors can burst into several fragments which will be difficult for the enclosure to withstand, so require very large containment systems. This issue can be mitigated by making the rotor from a stack of thinner discs, as explained in the section on rotors. This is because the catastrophic 
failure would release a fraction of the energy contained in the flywheel rotor. The enclosure design for high-speed FESS will contribute to half of the flywheel weight, whereas this factor would be two and half times larger for low speed FESS, according to [18]. The authors hold a different view on this multiplier, as do most flywheel manufacturers who adopt a range of stances to justify safety including placing flywheels in bankers for large composite rotors. Published literature on what is required to contain both composite and steel rotors is not readily available and no officially adopted standards currently exist, to the author's knowledge. One recent publication has proposed a standard [60], which is a useful step forward.

\section{FESS Characteristics}

The main characteristics of flywheels are a high cycle life (hundreds of thousands), long calendar life (more than 20 years), fast response, high round trip efficiency, high charge and discharge rates, high power density, high energy density [7,9], and low environmental impacts $[2,3,9,28,29,61]$. The state of charge can be easily measured from the rotational speed and is not affected by life or temperature [9]. On the downside, flywheel self-discharge at a much higher rate than other storage mediums and flywheel rotors can be hazardous, if not designed safely.

Flywheels have a long life time and very low operational and maintenance requirements. The cycle life is also high, compared to many other energy storage systems, as flywheels do not require long charge-discharge cycles. It can be charged and discharged rapidly, based on the application and functionality, and is not affected by the depth of discharge (DoD). The life time is estimated to be more than 20 years and a charge-discharge cycle life in excess of hundreds of thousands, with no deterioration in its performance $[3,28,29]$. The technology is capable of transferring large amounts of power in seconds, with a high roundtrip energy efficiency in the range of $90 \%-95 \%[1,2,18]$. It can deliver its stored energy and recharge quickly, in a matter of seconds. It is an environmentally friendly technology and there are no emissions as a result of its operation, since the material used is not hazardous to the environment $[18,29]$. The power and energy ratings of flywheels are independent and each can be optimized, based on the application of the energy storage. The power rating of a flywheel depends on the size of MG and associated power electronics, where its energy rating is determined by the size and speed of the rotor $[3,8]$.

There are a wide range of applications of flywheels in high power output for short periods; however, in addition to the rotor material, a longer storage period requires developing new rotor designs (e.g., larger diameter rotors and/or rotor laminations), to allow longer storage durations [8]. The size of FESS is an important characteristic which puts them in competition with other energy storage technologies. Flywheels can have power densities up to five to ten times that of batteries. Due to their relatively lower volume requirements and longer working life, they can replace batteries in certain applications, including in transportation and space vehicles [8].

\section{FESS Applications}

Flywheel applications range from large scale at the electrical grid level, to small scale at the customer level $[8,9]$. A high power and capacity is reached by arranging flywheels in banks, rather than by using large machines [62]. The best and most suitable applications of flywheels fall in the areas of high power for a short duration (e.g., $100 \mathrm{~s}$ of $\mathrm{kW} / 10 \mathrm{~s}$ of seconds) [6], when frequent charge-discharge cycles are involved [8]. The most common applications are power quality such as frequency and voltage regulation [2,63], pulsed power applications for the military [61], attitude control in space craft [61], UPS [18], load levelling [2], hybrid and electric vehicles [18,61], and energy storage applications [61]. As part of energy storage applications, flywheels perform storage applications both at the grid, as well as at the customer level. A brief description of some common applications associated with flywheel energy storage systems will now be given. 


\subsection{Power Quality}

As part of the power quality requirements, the system frequency and voltage need to be maintained to an acceptable level and deviations should be avoided. When the loads are added or subtracted from the grid, the system voltage and frequency will also be increased or reduced. Energy storage systems, especially those which are fast performing like flywheels, can quickly add or take power from the grid, to keep the system voltage and frequency within range [64]. Flywheels provide ride-through applications for interruptions of up to $15 \mathrm{~s}$ long and provide a means of switching between power sources without any service interruptions [2]. Flywheels can operate for up to tens of minutes for reactive power support, spinning reserve, and voltage regulation, to supply reliable electric power and improve the power quality in applications such as communication facilities and computer server centres [2]. As long as run down losses are kept low, durations can be extended to several hours, without losing excessive amounts of energy. In North Western Australia, a flywheel system has been integrated into a town's power supply to support the increased power demand during the tourist season [65]. Coral Bay, a wind energy operated power station, consisted of seven $320 \mathrm{~kW}$ low-load diesel generators with three $200 \mathrm{~kW}$ wind turbines. In 2007, the integration of a $500 \mathrm{~kW}$ flywheel virtual generator into the system allowed the wind turbines to provide up to $95 \%$ of Coral Bay's supply at peak times. The reported data shows that for nearly $900 \mathrm{~h}$ per year, $90 \%$ of the power station's total supply comes from wind generation. In addition, while maintaining the grid standards and improving the power quality, $80 \%$ of this total power is wind-generated for one-third of the year [65]. Another flywheel-based stabilisation system has been planned for the Marsabit wind farm, a remote community served by an isolated microgrid in northern Kenya. A $500 \mathrm{~kW}$ flywheel-based system will be integrated into the existing two $275 \mathrm{~kW}$ wind turbines and diesel generators. The PowerStore flywheel to be installed by ABB will stabilise the grid connection to maximise renewable energy penetration [66]. PowerStore is a flywheel-based stabilising generator which is mainly used for improving the power quality. It enables the integration and control of renewable wind and solar energy in the electrical grid. Acting like a static synchronous compensator (STATCOM), it combines an $18 \mathrm{MWs}$ (Megawatt second) low-speed flywheel with solid state converters that absorb or inject full energy in 1 millisecond [67]. The range of models from $500 \mathrm{~kW}$ to $1.5 \mathrm{MW}$ allows the configuration of either a grid support mode for MW scale grids, or as a virtual generator for use in smaller isolated grids.

\subsection{Frequency Regulation}

Frequency fluctuations occur as a result of variations between the loads and supply, where one exceeds the other. When demand exceeds supply, the generating plants are slowed down by the extra load, thus decreasing the system frequency. On the other hand, the generators accelerate and the frequency increases whenever the generation exceeds the demanded loads $[68,69]$. The frequency fluctuates every second, as demand varies and generators turn on and off. In order to avoid this, frequency regulation is applied, which demands the generators to hold capacity in reserve, to maintain the stability of generation and consumption. This ramping up and down of the generators not only increases the fuel cost and emissions, but also takes a minute or longer for some generating power plants to respond $[68,70]$.

A frequency regulation service is a very cyclic application requiring thousands of charge-discharge cycles in a year. Any storage device in this application will be very rarely "resting", due to the fact that it includes constant charging and discharging at variable rates, from very slow to rapid and deep cycling [70]. Today, grid operators look for 'fast-acting regulators' including flywheels and batteries to respond to the frequency regulation issue. Because of their fast response and frequent charge-discharge capabilities, flywheels are likely to dominate over batteries in this application. Similarly, the capability of flywheels to switch from full output to full absorption in seconds, puts them on a par with the immediate energy produced by gas fired power plants. Flywheel energy storage systems can deliver twice as much frequency regulation for each megawatt of power that they produce, while cutting carbon emissions in half [68,71]. The earliest, but shortest lifespan of a flywheel system reported 
for frequency regulation using renewables, was installed in Shimane, Japan, in 2003. This $200 \mathrm{~kW}$ Urenco Power Technology Flywheel was installed by Fuji electric to reduce system fluctuations due to wind generation. The diesel generators supporting the $1.8 \mathrm{MW}$ wind turbines were operating at a higher efficiency when the flywheel system was integrated. The system was decommissioned in 2004, as Urenco abandoned power quality operated flywheels and removed all previously installed units [65]. The largest power rated FESS for frequency regulation is the Joint European Torus (JET) Fusion Flywheel of the European Atomic Energy Community (EURATOM) located in Oxfordshire, UK [72]. JET uses the grid for powering electromagnets, and for generating fields to confine and ohmically heat hydrogen plasma. Experiments typically last $20 \mathrm{~s}$ and draw $1000 \mathrm{MW}$-a large fraction of the local Didcot Power Station's capacity [73]. There are two large flywheels capable of supplying up to $400 \mathrm{MW}$ for $30 \mathrm{~s}$ and an additional $300 \mathrm{MW}$ power is pulled from the grid to combine with the FESS, in order to satisfy the peak consumption of the JET pulse. The JET flywheels are charged up from the grid for several minutes, then quickly discharged into the required loads. Hence, distribution network congestion is avoided by reducing the demand on the grid during experiments [74]. A $20 \mathrm{MW}$ flywheel-based facility provides frequency regulations services to New York Independent System Operator (NYISO) in Stephentown, New York [29]. The facility is built and operated by Beacon Power and comprises 200 flywheels, each with a storage capacity of $100 \mathrm{~kW}$. The tests during early trials showed that $1 \mathrm{MW}$ of fast response flywheel storage could produce up to $30 \mathrm{MW}$ of regulation service; two to three times better than an average Independent System Operator (ISO) generator. A second 20 MW frequency-regulation facility in the Hazle Township of Pennsylvania is commissioned by Spindle Grid Regulation, LLC. This zero emission facility is designed for 20 year-life and at least 100,000 full-depth discharge cycles. It is comprised of 200 Beacon Power's $100 \mathrm{~kW}$ ( $25 \mathrm{kWh}$ ) flywheels connected in parallel, which can respond in less than $2 \mathrm{~s}$ [75].

\subsection{Voltage Sag Control}

Voltage sag problems are created due to load unbalance or faults in the power grid, causing a decrease in voltage magnitude. Voltage sags due to unbalanced loads occur when large amounts of power for a short period of time is absorbed by the load, which will decrease the voltage and cause voltage drop problems $[69,76]$.

Voltage sag has become one of the major power quality problems affecting sensitive loads such as modem industrial manufacturing like semiconductor production, food processing and paper making, sensitive microprocessors, and high frequency power electronic devices [76]. Further drawbacks of voltage sag in three-phase power networks are increased line losses, neutral conductor overloads, and extra rotating losses in drives [69]. About $92 \%$ of the power quality problems are as a result of voltage sag and $80 \%$ of these occasions last for only $20-50 \mathrm{~ms}$ [76].

Traditionally, voltage sag has been compensated for by generation reserves adding power to the system, when demanded. The recent approach is to engage energy storage systems in mitigating the voltage problems in power networks. The energy storage system is used to store the energy in times when excessive power is required, in order to keep the grid voltage fixed. This reduces the cost and eliminates the need for oversized generating units [69].

FESS, with their excellent characteristics, can be viable alternatives to other storage systems for this application. Particularly, a fast response, high power density, and frequent charge-discharge cycle capability, are the best attributes of flywheels for voltage compensation applications [69]. A $10 \mathrm{MJ}$ flywheel energy storage system for high quality electric power and reliable power supply from the distribution network, was tested in the year 2000. It was able to keep the voltage in the distribution network within $98 \%-102 \%$ and had the capability of supplying $10 \mathrm{~kW}$ of power for $15 \mathrm{~min}$ [9]. In 2005, a flywheel-based grid stabilising generator (PowerStore) commenced operation in Flores Island, Portugal. It has been used to perform a frequency and voltage ride through to safeguard conventional grids and allows the integration of renewable generation from wind and solar sources. The PowerStore with a $500 \mathrm{~kW}$ rated power and $60 \mathrm{~s}$ duration capability is still operational [65]. 


\subsection{UPS}

A short term (seconds to minutes) energy storage device with control electronics is referred to as uninterruptible power supply (UPS). A UPS is one of the existing markets and the most successful application for high power flywheels to supply power for occasions which usually don't last longer than $15 \mathrm{~s}$. More than $80 \%$ of the power outages last for less than a second [8] and $97 \%$ of them last for less than $3 \mathrm{~s}$ [10]; however, this causes voltage and frequency problems, as well as power interruptions. In these applications, the UPS, as a backup storage, bridges the gap between the loss of the grid and the start of backup sources during an interruption.

The most developed and widely used storage medium in UPS applications is batteries. FESS can be used as a substitute for batteries or in combination with batteries in UPS systems [12]. In cases with only flywheels as a backup storage, sufficient power is provided by the flywheel to run the system, until the power source is restored or a standby power source comes online. Depending on the level of power required, 10-15 s of back up support is enough to meet the demand loads, without transferring to the generator set power $[8,10]$. This is the case when power outages last less than $15 \mathrm{~s}$. Meanwhile, in diesel-rotary UPS with diesel generators for long-term outages, the diesel engines commonly start and accept 100\% load within 3-4 s and flywheels are best suited to bridge the power, until the generators are fully operated and synchronized. As a result, either scenario can be accomplished, with flywheels acting as energy storage systems for UPS applications.

In addition, flywheels are used in combination with batteries in UPS systems requiring longer durations. A flywheel can deal with shorter interruptions, while batteries can be saved for longer outages. This will save the battery from frequent charge-discharge, which will further increase its lifetime [12]. Usually, flywheels and batteries are combined for applications requiring a mix and match between energy density and cost, which cannot be otherwise achieved with one of these storage systems [71]. Many manufacturers around the world have developed flywheel systems for UPS. To name a few, one of the earliest flywheels for on-site power applications was built in Munchen, Germany, in 1973. It was rated for $155 \mathrm{MW}$ power and 0.93 power factor, for a pulsed duration of $9.7 \mathrm{~s}$. In the following years, this flywheel was complemented with two more flywheels to utilise a flywheel generator system for high energy fusion experiments. The system was fully commissioned in 1987 and the total rated power and pulsed duration capability of the system was increased to $387 \mathrm{MW}$ and $12 \mathrm{~s}$, respectively [65]. A hybrid microgrid supplying heat and electricity to an industrial/airport facility in an island in Alaska was commissioned in 1999. Originally consisting of a $225 \mathrm{~kW}$ wind turbine, and two $150 \mathrm{~kW}$ diesel generators, the system was upgraded with a $160 \mathrm{~kW}$ FESS by Beacon technology in 2014. In addition to efficiency improvements, it has also provided fuel savings of up to $30 \%$ [65]. Piller $\mathrm{GmbH}$ has installed a FESS in a combined heat and power station to supply a semiconductor facility in Dresden, Germany. The integrated $5 \mathrm{MW}$ flywheel subsystem can supplement the $30 \mathrm{MW}$ plant with $5 \mathrm{~s}$ storage [7]. A battery-free UPS system has been announced by VYCON to protect a light-out data centre located in Texas, US. The system will involve multiple $750 \mathrm{kVA}$ double conversion UPS modules, paired with an $8 \mathrm{MW}$ (300 kW power rating per unit) FESS. Deploying approximately 1MW of clean energy, a similar flywheel system has also been planned to protect EasyStreet Online Service's data centre in California, US [77]. Similarly, the control centre of Austin Energy is protected by a 4.8 MW flywheel UPS by VYCON. Austin Energy, one of the largest electric utilities in US, supplies approximately 400,000 customers and of a population of about one million. The attributes associated with a battery-free flywheel system are reduced downtime, no battery maintenance requirement, and savings on cooling of the environment for batteries.

\subsection{Transportation}

In transportation, flywheels are used in hybrid and electric vehicles to store energy, for use when harsh acceleration is required or to assist with uphill climbs. In hybrid vehicles, the constant power is provided by the internal combustion engines to keep the vehicle running at a constant optimum speed, reducing fuel consumption, air and noise pollution, and extending the engine life by reducing 
maintenance requirements $[7,8]$. At the same time, energy from regenerative braking during vehicle slowdown is stored in flywheels, which will be supplied back to provide a boost during acceleration or climbing hills $[7,8,59]$. The only competitors to flywheels in hybrid vehicle applications are chemical batteries and ultra-capacitors. However, ultra-capacitors suffer from a low energy density and higher cost. Flywheels rank better than batteries based on their longer life time, higher power density, higher efficiency, and frequent charge-discharge capability [8]. Furthermore, flywheels are developed for rail applications, both for hybrid and electric systems. They also find a place in gas turbine trains for the same purpose. The desired speed and maximum weight of the train determines the power and energy requirements. It is estimated that $30 \%$ of the braking energy could be recovered by this system, due to receptivity issues [8]. In electrical vehicles with chemical batteries as their source of propulsion, flywheels are considered to cope well with a fluctuating power consumption. This will prolong the lifetime of the battery as its charge-discharge cycles become more regular [10]. In train energy recovery systems, flywheels are installed at stations or substations to recover energy through regenerative braking, and supply it back into the system for traction purposes. Flywheels are well suited for this application due to the high rate of charge-discharge cycles needed. In addition, it allows voltage sag control for transmission and distribution lines, without increasing the line capacity of the railway. A number of flywheels for trackside energy recovery systems have been demonstrated by URENCO and Calnetix [78]. In April 2014, VYCON Inc. installed a FESS for the Los Angeles Country Metropolitan Transportation Authority (LA Metro) Red line (MRL), to recover the braking energy from trains. MRL provides rail subway service connecting downtown to San Fernando Valley through six-car trains with AC or DC traction systems [79]. VYCON's flywheel, known as Metro's Wayside Energy Storage Substation (WESS), can recover $66 \%$ of the braking train energy [80]. The collected data, after six months of operation, showed $20 \%$ energy savings (approximately $541 \mathrm{MWh}$ ), which is enough to power 100 average homes in California [79]. A total of 190 metro systems operating in 9477 stations and approximately $11,800 \mathrm{~km}$ of track has been reported globally [13]. The introduction of energy storage into rail transit for braking energy recovery can potentially reduce $10 \%$ of the electricity consumption, while achieving cost savings of $\$ 90,000$ per station [81]. Flywheels are also used in roller coaster launch systems to accumulate the energy during downhill movements and then rapidly accelerate the train to reach uphill positions, using electromagnetic, hydraulic, and friction wheel propulsion [82]. The Incredible Hulk roller coaster at an adventure theme park in Orlando, Florida, uses several $4500 \mathrm{~kg}$ flywheels to propel the system. The flywheels charge continuously at about $200 \mathrm{~kW}$ and then discharge at $8 \mathrm{MW}$, to launch the train [13]. Since the late 2000s, the use of flywheel hybrid storage systems in motorsports has seen major developments, beginning with Formula 1 and followed by the highest class of World Endurance Championship (WEC) [13]. Williams Hybrid Power (WHP), part of Williams Group of companies, pioneered the use of flywheel energy storage in motorsport. WHP's electric flywheel was used in Porsche Motorsport on their 2010911 GT3 R Hybrid endurance racing car. This car competed in several endurance races in 2010, including the $24 \mathrm{~h}$ Nürburgring race, where it led the race by two laps until 22nd $h$, before retiring due to an engine-related failure-an unrelated problem to the hybrid system. The following year, the GT3 R secured first position in the VLN race at the Nordschleiefe [83]. Porsche hybrid's latest version, the 918 RSR hybrid concept sports car with electric flywheel energy storage, was announced at the 2010 Detroit Motorshow. In March 2012, WHP was announced as the hybrid energy storage supplier for Audi R18 e-tron Quattro. WHP's entirely new design flywheel (150 kW power, 45,000 rpm speed) for Audi made history by becoming the first hybrid car to win Le Mans, the most demanding race in the world, in 2010, 2013, and 2014 [84]. In public transport, city buses are an ideal application for electric flywheel hybridisation, due to their higher mass and frequent start-stop nature. The technology can save fuel and reduce greenhouse gas emissions by up to $30 \%$ [83]. WHP started developing flywheel energy storage for use in buses for the Go-Ahead Group in March 2012. It also developed a kinetic energy recovery system (KERS) for GKN Gyrodrive in April 2014. The GKN has recently demonstrated a design for use in city buses [85]. 


\subsection{Spacecraft}

Flywheels find applications in space vehicles where the primary source of energy is the sun, and where the energy needs to be stored for the periods when the satellite is in darkness $[7,8]$. FES for the international space station (ISS) was discussed in 1961 and was first proposed in the 1970s [7]. For the past decade, the NASA Glenn Research Centre (GRC) has been interested in developing flywheels for space vehicles. Initially, designs used battery storage, but now, FES are being considered in combination with or to replace batteries $[7,8]$. The combined functionality of batteries and flywheels will improve the efficiency, and reduce the spacecraft mass and cost [7]. The proposed flywheel system for NASA has a composite rotor and magnetic bearings, capable of storing an excess of $15 \mathrm{MJ}$ and peak power of $4.1 \mathrm{~kW}$, with a net efficiency of $93.7 \%$. Based on the estimates by NASA, replacing space station batteries with flywheels will result in more than US $\$ 200$ million savings $[7,8]$. It has been reported that a flywheel system would be significantly smaller and offer a better weight reduction than the use of $\mathrm{NiH}_{2}$ battery devices for use on EOS-AMI-type spacecraft. It has been shown that the flywheel offers a $35 \%$ reduction in mass, $55 \%$ reduction in volume, and a $6.7 \%$ area reduction for solar array [86]. FESS is the only storage system that can accomplish dual functions, by providing satellites with renewable energy storage in conjunction with attitude control [24,25].

\subsection{Renewables}

Flywheels can assist in the penetration of wind and solar energy in power systems by improving system stability. The fast response characteristics of flywheels make them suitable in applications involving RES for grid frequency balancing. Power oscillations due to solar and wind sources are compensated for by storing the energy during sunny or windy periods, and are supplied back when demanded $[9,10]$. Flywheels can be used to rectify the wind oscillations and improve the system frequency; whereas, in solar systems, they can be integrated with batteries to improve the system output and elongate the battery's operational lifetime [9].

The authors in [18] indicate that the formation of a hybrid system by the addition of wind turbines and photovoltaic panels could not result in fuel savings, as expected. This is because diesel generators, even unloaded, will consume up to $40 \%$ fuel. Diesel generators should only be started when demanded and shut down most of the time. Therefore, flywheel energy storage systems can reduce frequent start/shut-down cycles of the diesel generators; thus reducing fuel consumption and bridging the power fluctuations [18]. The current authors see a great benefit of flywheels backing up solar PV, since they can cope with the high cycles due to the cloud passing, yet provide ride through, as long as standing losses are kept low. There has been a wide range of flywheel systems developed for the penetration of renewable energy systems. For example, ABB's PowerStore, Urenco Power, Beacon Power, and VYCON technology, have all provided flywheel-based systems for wind and solar applications. On a larger scale, the world's first high penetration solar PV diesel power stations were installed in 2010, supplying the towns of Nullagine and Marble Bar in Western Australia. A FESS is operated as a UPS system, to allow maximum solar power injection during sunshine and ramp up diesel generators when the sun is obscured. This enables a saving of 405,000 litres of fuel and 1100 metric tons of greenhouse gas emissions each year. Moreover, the integration of flywheels in the system has helped the PV system to supply $60 \%$ of the average daytime energy for both towns, generating $1 \mathrm{GWh}$ of renewable energy per year [65].

\subsection{Military}

In the military, a recent trend has been towards the inclusion of electricity in military applications, such as in ships and other ground vehicles, as well as for weapons, navigation, communications, and their associated intelligent systems. This use of electric energy at different rates and different power levels requires energy storage to respond rapidly and reliably to this variable energy demand [8]. Hybrid electric power is essential for future combat vehicles, based on their planned electrically 
powered applications. Flywheels appear as an appropriate energy storage technology for these applications. They are combined with supercapacitors to provide power for high speed systems requiring power in less than $10 \mu \mathrm{s}$.

Flywheels are also likely to find applications in the launching of aircraft from carriers. Currently, these systems are driven by steam accumulators to store the energy; however, flywheels could replace these accumulators to reduce the size of the power generating systems that would otherwise be sized for the peak power load [8]. A FESS is integrated into a microgrid serving the US Marine Corp in California, to provide energy storage applications throughout the entire distributed generation at the base [65]. The purpose of the project is to provide energy security to military facilities using renewable energy. It is a network of interconnected smaller microgrids that are nested into a $1.1 \mathrm{MW}$ bigger-scale microgrid, that include solar PV systems, diesel generators, batteries, and $60 \mathrm{~kW}, 120 \mathrm{kWh}$ FESS [87]. The flywheel storage is intended to decrease the dependency on diesel generators by about $40 \%$ and provide peak shaving applications by mainly supplying high power loads such as elevators. In addition to extending the lifespan of the batteries, the FESS is estimated to work for 50,000 cycles and have a lifespan of 25 years [87].

\section{Recommendations for Future Research}

Although the flywheel is one of the earliest forms of energy storage, compact, reliable, low maintenance flywheels have only become available relatively recently. The numbers produced have been small, and the use of more exotic materials and their processing, such as carbon fibre composites, have kept the cost at about five times higher than steel flywheels [10,18]. New, innovative designs based on steel overcome the concern about safety for highly stressed rotors, which can now operate at much higher tip speeds than was considered safe for monolithic steel rotors [88]. Steel has the benefit that the material and processing routes are well established and understood to the supply base which is already there, for low cost manufacturing at the all critical batch scales of $10 \mathrm{~s}$ to $1000 \mathrm{~s}$. Steel is easily recyclable in comparison to batteries, although recycling will not need to be done for decades given an effective infinite calendar life and cycle life of many $10 \mathrm{~s}$ of thousands.

Another concern relates to the charge holding ability of flywheels, since the losses in currently available flywheels are high. These losses are mechanical (drag, bearing, friction), electrical (hysteresis, eddy current, copper), and power converter-related (switching and conduction) [89]. If flywheel losses can be kept to around $10 \%-20 \%$ run down per $24 \mathrm{~h}$, given the available technologies and the lower speeds of the steel flywheel, the possibility for these applications is certainly promising. The vacuum needed for this is not unduly high and will be held by means of a hermetically sealed system, only requiring occasional re-pumping. The majority of the weight can be levitated on passive magnetic bearings, with inevitable losses in the lightly loaded ball bearing system being well within the $20 \%$ run down loss allowance. The remaining loss is the electromagnetic drag in the generator and this depends on the design. Since a flywheel for this duty is likely to have an electrical machine of $\mathrm{kW}$ rating similar to the kWh rating, numerically, the electromagnetic drag of a well-designed system can also be kept within the loss budget.

\section{Conclusions}

This paper has presented a critical review of FESS with reference to its main components and applications. The structure and components of the flywheel are introduced and the main types for electric machines, power electronics, and bearing systems for flywheel storage systems are described in detail. The main applications of FESS in power quality improvement, uninterruptible power supply, transportation, renewable energy systems, and energy storage are explained, and some commercially available flywheel storage prototypes, along with their operation under each application, are also mentioned. FESS offer the unique characteristics of a very high cycle and calendar life, and are the best technology for applications which demand these requirements. A high power capability, instant response, and ease of recycling are additional key advantages. Given the demand for ESS is expanding 
substantially, and that FESS has these unique attributes, the future for FESS remains very bright, even in a time when the cost of Li-ion and other chemistry battery technology continues to reduce. Future work will include the detailed modelling and analysis of a flywheel system for backup power and grid support applications.

Acknowledgments: This work has been funded by European Union's Erasmus Mundus under INTACT project, the City University Graduate School and the City Future Fund.

Conflicts of Interest: The authors declare no conflict of interest.

\section{References}

1. Medina, P.; Bizuayehu, A.W.; Catalao, J.P.S.; Rodrigues, E.M.G.; Contreras, J. Electrical Energy Storage Systems: Technologies' State-of-the-Art, Techno-economic Benefits and Applications Analysis. In Proceedings of the 47th Hawaii International Conference on System Sciences, Waikoloa, HI, USA, 6-9 January 2014; pp. 2295-2304.

2. Chen, H.; Cong, T.N.; Yang, W.; Tan, C.; Li, Y.; Ding, Y. Progress in electrical energy storage system: A critical review. Prog. Nat. Sci. 2009, 19, 291-312. [CrossRef]

3. Hadjipaschalis, I.; Poullikkas, A.; Efthimiou, V. Overview of current and future energy storage technologies for electric power applications. Renew. Sustain. Energy Rev. 2009, 13, 1513-1522. [CrossRef]

4. Del Granado, P.C.; Wallace, S.W.; Pang, Z. The value of electricity storage in domestic homes: A smart grid perspective. Energy Syst. 2014, 5, 211-232. [CrossRef]

5. Fu, B.Q.; Hamidi, A.; Nasiri, A.; Bhavaraju, V.; Krstic, S.B. The Role of Energy Storage in a Microgrid Concept. IEEE Electr. Mag. 2013, 1, 21-29. [CrossRef]

6. Vafakhah, B.; Masiala, M.; Salmon, J.; Knight, A. Emulation of flywheel energy storage systems with a PMDC machine. In Proceedings of the 18th IEEE International Conference on Electric Machines, Vilamoura, Algarve, Portugal, 6-9 September 2008; pp. 1-6.

7. Liu, H.; Jiang, J. Flywheel energy storage-An upswing technology for energy sustainability. Energy Build. 2007, 39, 599-604. [CrossRef]

8. Hebner, R.; Beno, J.; Walls, A. Flywheel batteries come around again. IEEE Spectr. 2002, 39, 46-51. [CrossRef]

9. Bolund, B.; Bernhoff, H.; Leijon, M. Flywheel energy and power storage systems. Renew. Sustain. Energy Rev. 2007, 11, 235-258. [CrossRef]

10. Sebastián, R.; Alzola, R.P. Flywheel energy storage systems: Review and simulation for an isolated wind power system. Renew. Sustain. Energy Rev. 2012, 16, 6803-6813. [CrossRef]

11. Emadi, A.; Nasiri, A.; Bekiarov, S.B. Uninterruptable Power Supplies and Active Filters; Illinois Institute of Technology: Chicago, IL, USA; CRC Press: Washington, DC, USA, 2005.

12. DOE/EE. Flywheel Energy Storage. An Alternative to Batteries for Uninterruptible Power Sypply Systems; U.S Department of Energy (DOE), Energy Efficiency and Renewable Energy: Washington, DC, USA, 2003.

13. Bender, D. Flywheels; Sandia Report; Sandia National Laboratories: Albuquerque, ME, USA, 2015.

14. Sabihuddin, S.; Kiprakis, A.; Mueller, M. A Numerical and Graphical Review of Energy Storage Technologies. Energies 2014, 8, 172-216. [CrossRef]

15. Farhadi, M.; Member, S.; Mohammed, O. Energy Storage Technologies for High-Power Applications. IEEE Trans. Ind. Appl. 2016, 52, 1953-1961. [CrossRef]

16. Daoud, M.I.; Abdel-Khalik, A.S.; Massoud, A.; Ahmed, S.; Abbasy, N.H. On The Development of Flywheel Storage Systems for Power System Applications: A Survey. In Proceedings of the 20th International Conference on Electrical Machines ( ICEM), Marseille, France, 2-5 September 2012; pp. 2119-2125.

17. Kenny, B.H.; Kascak, P.E.; Jansen, R.; Dever, T. Control of a High Speed Flywheel System for Energy Storage in Space Applications. IEEE Trans. Ind. Appl. 2005, 41, 1029-1038. [CrossRef]

18. Pena-Alzola, R.; Sebastián, R.; Quesada, J.; Colmenar, A. Review of Flywheel based Energy Storage Systems. In Proceedings of the 2011 International Conference on Power Engineering, Energy and Electrical Drives, Malaga, Spain, 11-13 May 2011.

19. Yu, Y.; Wang, Y.; Sun, F. The Latest Development of the Motor/Generator for the Flywheel Energy Storage System. In Proceedings of the 2011 International Conference on Mechatronic Science, Electric Engineering and Computer (MEC), Jilin, China, 19-22 August 2011; pp. 1228-1232. 
20. Awadallah, M.A.; Venkatesh, B. Energy Storage in Flywheels: An Overview Le stockage dénergie dans les volants: Apercu. Can. J. Electr. Comput. Eng. 2015, 38, 183-193. [CrossRef]

21. Genta, G. Kinetic Energy Storage: Theory and Practice of Advanced Flywheel Systems; Butterworth Heinemann Ltd.: London, UK, 1985.

22. Shelke, P.R.S.; Dighole, D.G. A Review paper on Dual Mass Flywheel system. Int. J. Sci. Eng. Technol. Res. 2016, 5, 326-331.

23. Östergard, R. Flywheel Energy Storage-A Conceptual Study. Master's Thesis, Uppsala Universitet, Uppsala, Sweden, 2011.

24. Babuska, V.; Beatty, S.; DeBlonk, B.; Fausz, J. A review of technology developments in flywheel attitude control and energy transmission systems. In Proceedings of the 2004 IEEE Aerospace Conference, Big Sky, MT, USA, 6-13 March 2004; Volume 4, pp. 2784-2800.

25. Bitterly, J.G. Flywheel technology past, present, and 21st century projections. In Proceedings of the Thirty-Second Intersociety Energy Conversion Engineering Conference (IECEC-97), Honolulu, HI, USA, 27 July-1 August 1997; Volume 4, pp. 2312-2315.

26. Pena-Alzola, R.; Campos-Gaona, D.; Martin, O. Control of Flywheel Energy Storage Systems as Virtual Synchronous Machines for Microgrid. In Proceedings of the 2015 IEEE 16th Workshop on Control Modelling for Power Electronics (COMPEL), Vancouver, BC, Canada, 12-15 July 2015; Volume 1, pp. 1-7.

27. De Oliveira, J.G. Power Control Systems in a Flywheel based All-Electric Driveline. Ph.D. Thesis, Uppsala Universitet, Uppsala, Sweden, 2011.

28. Parfomak, P.W. Energy Storage for Power Grids and Electric Transportation: A Technology Assessment; Congressional Research Services: Washington, DC, USA, 2012.

29. Akhil, A.A.; Huff, G.; Currier, A.B.; Kaun, B.C.; Rastler, D.M.; Chen, S.B.; Cotter, A.L.; Bradshaw, D.T.; Gauntlett, W.D. DOE/EPRI 2013 Electricity Storage Handbook in Collaboration with NRECA; U.S. Department of Energy: Oak Ridge, TN, USA, 2013.

30. Su, W.; Jin, T.; Wang, S. Modeling and Simulation of Short-term Energy Storage: Flywheel. In Proceedings of the 2010 International Conference on Advances in Energy Engineering Modeling (ICAEE), Beijing, China, 19-20 June 2010; pp. 9-12.

31. Meng, Y.M.; Li, T.C.; Wang, L. Simulation of controlling methods to flywheel energy storage on charge section. In Proceedings of the Third International Conference on Electric Utility Deregulation and Restructuring and Power Technologies (DRPT 2008), Nanjing, China, 6-9 April 2008; pp. 2598-2602.

32. Guo, Z.; Mu, X.; Bai, Z.; Cao, B. Research on the control of flywheel battery. J. Appl. Sci. 2007, 7, 3312-3316.

33. Zhang, X.; Yang, J. An improved discharge control strategy with load current and rotor speed compensation for high-speed flywheel energy storage system. In Proceedings of the 17th International Conference on Electrical Machines and Systems (ICEMS), Hangzhou, China, 22-25 October 2014; pp. 318-324.

34. Samineni, S.; Johnson, B.K.; Hess, H.L.; Law, J.D. Modeling and Analysis of a Flywheel Energy Storage System with a Power Converter Interface. In Proceedings of the International Conference on Power Systems Transients (IPST 2003), New Orleans, LA, USA, 1-4 June 2003; Volume 4, pp. 1-6.

35. Bakay, L.; Dubois, M.; Viarouge, P.; Ruel, J. Mass-losses relationship in an optimized 8-pole radial AMB for Long Term Flywheel Energy Storage. In Proceedings of the IEEE AFRICON 2009, Nairobi, Kenya, 23-25 September 2009; pp. 1-5.

36. Dynamic Boosting Systems (DBS). Laminated Steel Energy Storage Flywheel Technology. Available online: http:/ / dynamicboost.com/flywheel-technology-energy-storage (accessed on 5 February 2017).

37. Chang, L. Comparison of AC drives for electric vehicles-A report on experts' opinion survey. IEEE Aerosp. Syst. Mag. 1994, 9, 7-11. [CrossRef]

38. Carrillo Arroyo, E.L. Modeling and Simulation of Permanent Magnet Synchronous Motor Drive System. Master's Thesis, University Of Puerto Rico, San Juan, Puerto Rico, 2006.

39. Mounika, K.; Babu, B.K. Sinusoidal and Space Vector Pulse Width Modulation for Inverter. Int. J. Eng. Trends Technol. 2013, 4, 1012-1017.

40. Rashid, M.H.; Kumar, N.; Kulkarni, A.R. Power Electronics: Devices, Circuits, and Applications, 4th ed.; Pearson: Essex, UK, 2014.

41. Zhou, L.; Qi, Z.P. Modeling and control of a flywheel energy storage system for uninterruptible power supply. In Proceedings of the 2009 International Conference on Sustainable Power Generation and Supply, Nanjing, China, 6-7 April 2009; pp. 1-6. 
42. Khaterchi, M.; Belhadj, J.; Elleuch, A.M. Participation Of Direct Drive Wind Turbine To The Grid Ancillary Services Using A Flywheel Energy Storage System. In Proceedings of the IEEE 2010 7th International Multi-Conference on Systems, Signals Devices, Amman, Jordan, 27-30 June 2010.

43. Gayathri, N.S.; Senroy, N. Wind turbine with flywheel for improved power smoothening and LVRT. In Proceedings of the IEEE Power and Energy Society General Meeting, Vancouver, BC, Canada, 21-25 July 2013; pp. 1-5.

44. Rashid, M. Power Electronics Handbook, 3rd ed.; Butterworth Heinemann: London, UK, 2011.

45. Wilamoswski, B.M.; Irwin, J.D. The Industrial Electronics Handbook: Power Electronics And Motor Drives. In Power Electronics and Motor Drives, 2nd ed.; CRC Press, Taylor and Francis Group: New York, NY, USA, 2011.

46. Suvire, G.O.; Molina, M.G.; Mercado, P.E. Improving the Integration of Wind Power Generation Into AC Microgrids Using Flywheel Energy Etorage. IEEE Trans. Smart Grid 2012, 3, 1945-1954. [CrossRef]

47. Friedli, T.; Kolar, J.W.; Rodriguez, J.; Wheeler, P.W. Comparative evaluation of three-phase AC-AC matrix converter and voltage DC-link back-to-back converter systems. IEEE Trans. Ind. Electr. 2012, 59, 4487-4510. [CrossRef]

48. Wang, B.; Venkataramanan, G. Dynamic Voltage Restorer Utilizing a Matrix Converter and Flywheel Energy Storage. IEEE Trans. Ind. Appl. 2009, 45, 222-231. [CrossRef]

49. Gamboa, P.; Pinto, S.F.; Silva, J.F.; Margato, E. A Flywheel Energy Storage System with Matrix Converter Controlled Permanent Magnet Synchronous Motor. In Proceedings of the 2008 18th International Conference on Electric Machines, Vilamoura, Algarve, Portugal, 6-9 September 2008; pp. 232-236.

50. Chang, X.; Li, Y.; Zhang, W.; Wang, N.; Xue, W. Active Disturbance Rejection for a Flywheel Energy Storage System. IEEE Trans. Ind. Electron. 2015, 62, 991-1001. [CrossRef]

51. Elserougi, A.; Abdel-khalik, A.; Massoud, A.; Ahmed, S. Flywheel Energy Storage System Based on Boost DC-AC Converter. In Proceedings of the IET Conference on Renewable Power Generation (RPG 2011), Edinburgh, UK, 6-8 September 2012; pp. 1725-1732.

52. Jibin, Z.; Kai, L.; Mei, Z.; Jianhui, H. Simulation of Flywheel Energy Storage System ( FESS ) Using Z-Source Inverter. In Proceedings of the 2010 International Conference on Electric Machines and Systems, Incheon, Korea, 10-13 October 2010; pp. 266-269.

53. Kim, H.; Sul, S. A Novel Filter Design for Output LC Filters of PWM Inverters. J. Power Electron. 2011, 11, 74-81. [CrossRef]

54. Santiago, W. Inverter Output Filter Effect on PWM Motor Drives of a Flywheel Energy Storage System; Glenn Research Center: Cleveland, OH, USA, 2004.

55. Strasik, M.; Johnson, P.E.; Day, A.C.; Mittleider, J.; Higgins, M.D.; Edwards, J.; Schindler, J.R.; Mccrary, K.E.; Mciver, C.R.; Carlson, D.; et al. Design, Fabrication, and Test of a 5-kWh/100-kW Flywheel Energy Storage Utilizing a High-Temperature Superconducting Bearing. IEEE Trans. Appl. Supercond. 2007, 17, $2133-2137$. [CrossRef]

56. Zhang, C.; Tseng, K.J. A novel flywheel energy storage system with partially-self-bearing flywheel-rotor. IEEE Trans. Energy Convers. 2007, 22, 477-487. [CrossRef]

57. Zhang, C.; Tseng, K.J. Design and control of a novel flywheel energy storage system assisted by hybrid mechanical-magnetic bearings. Mechatronics 2013, 23, 297-309. [CrossRef]

58. Subkhan, M.; Komori, M. New Concept for Flywheel Energy Storage System Using SMB and PMB. IEEE Trans. Appl. Supercond. 2011, 21, 1485-1488. [CrossRef]

59. Faias, S.; Santos, P.; Sousa, J.; Castro, R. An Overview on Short and Long-Term Response Energy Storage Devices for Power Systems Applications. Renew. Energy Power Qual. 2008, 1, 442-447.

60. Bender, D. Recommended Practices for the Safe Design and Operation of Flywheels; U.S. Department of Energy: Oak Ridge, TN, USA, 2015.

61. Okou, R.; Sebitosi, A.B.; Khan, A.; Pillay, P. The potential impact of small-scale flywheel energy storage technology on Uganda's energy sector. J. Energy S. Afr. 2009, 20, 14-19.

62. Beacon Power LCC. Beacon POWER's Operating Plant in Stephentown, New York. Available online: http:/ / beaconpower.com/stephentown-new-york/ (accessed on 10 February 2017).

63. Whittingham, M.S. History, Evolution, and Future Status of Energy Storage. Proc. IEEE 2012, 100, $1518-1534$. [CrossRef] 
64. Jiancheng, Z.; Lipei, H.; Zhiye, C.; Su, W. Research on flywheel energy storage system for power quality. In Proceedings of the International Conference on Power Systems Technology, Kunming, China, 13-17 October 2002; Volume 1, pp. 496-499.

65. US Department of Energy Global Energy Storage Database. Available online: http://www. energystorageexchange.org/projects (accessed on 1 February 2017).

66. Kenya First Flywheel Energy Storage Technology to Be Set Up in Marsabit. Available online: https:// kenyaenergyfuture.wordpress.com/tag/powerstore/ (accessed on 1 February 2017).

67. ABB Microgrid Solution to Boost Renewable Energy Use by Remote Community in Kenya. Available online: http://www.abb.com/cawp/seitp202/118e562a8edb8d40c1257eb400446361.aspxglobal/seitp/ seitp202.nsf (accessed on 1 February 2017).

68. Hawkins, D. Flywheels Keep the Grid in Tune. IEEE Spectrum, 27 July 2011.

69. Al-Diab, A.; Sourkounis, C. Unbalanced Voltage Drops Compensations Using Flywheel Energy Storage System. In Proceedings of the 11th International Conference on Electrical Power Quality Utilisation, Lisbon, Portugal, 17-19 October 2011; pp. 1-6.

70. Lazarewicz, M.L.; Rojas, A. Grid Frequency Regulation by Recycling Electrical Energy in Flywheels. In Proceedings of the IEEE Power Engineering Society General Meeting 2004, Denver, CO, USA, 6-10 June 2004; Volume 2, pp. 2038-2042.

71. Boicea, V.A. Energy Storage Technologies: The Past and the Present. Proc. IEEE 2014, 102, 1777-1794. [CrossRef]

72. EFDA JET Fusion Flywheel. Available online: https://www.euro-fusion.org/2010/01/jets-flywheels-2/ (accessed on 1 February 2017).

73. Keen, B.E.; Kupschus, P. JET Joint Undertaking Progress Report, JET-Operation and Developement: Pulsed Power Supplies for JET Coils; JET Joint Undertaking: Abingdon, UK, 1987.

74. EUROfusion, 2016. Spot on JET Technology: Power Supply. Available online: https://www.euro-fusion. org/fusion/jet-tech/jets-flywheels/ (accessed on 10 February 2017).

75. Beacon Power. 20 MW Flywheel Frequency Regulation Plant; Final Technology Performance Report; Beacon Power: Tyngsboro, MA, USA, 2016.

76. Zhou, L.; Qi, Z. Modeling and Simulation of Flywheel Energy Storage System with IPMSM for Voltage Sags in Distributed Power Network. In Proceedings of the 2009 IEEE International Conference on Mechatronics and Automation, Changchun, China, 9-12 August 2009; pp. 5046-5051.

77. EasyStreet Ramps Up Data Center Operations, Deploys Additional VYCON Flywheel Systems to Protect Its Green Data Center. Available online: https:/ /www.calnetix.com/newsroom/press-release/easystreetramps-data-center-operations-deploys-additional-vycon-flywheel (accessed on 1 February 2017).

78. Tarrant, C. Kinetic Energy Storage Wins Acceptance. Available online: http://www.railwaygazette.com/ news/single-view/view / kinetic-energy-storage-wins-acceptance.html (accessed on 12 February 2017).

79. VYCON Technology Allows Los Angeles Metro to be First Transit Agency in U.S. Using Flywheels to Achieve Nearly 20 Percent in Rail Energy Savings. Available online: https:/ /www.calnetix.com/newsroom/ press-release/vycon-technology-allows-los-angeles-metro-be-first-transit-agency-us-using (accessed on 1 February 2017).

80. Castro, F.; Ng, L.S.B.; Dombek, A.; Solis, O.; Turner, D.; Bukhin, L.; Thompson, G. La Metro Red Line Wayside Energy Storage Substation Revenue Service Regenerative Energy Saving Results. In Proceedings of 2014 Joint Rail Conference (JRC 2014), Colorado Springs, CO, USA, 2-4 April 2014; pp. 1-5.

81. Schroeder, P.; Yu, D.T. Guiding the Selection and Application of Wayside Energy Storage Technologies for Rail Transit and Electric Utilities, Transit Cooperative Research Program; Contractor's Final Report for TCRP Project J6/Task 75; Transport Research Board: Washington, DC, USA, 2010.

82. Bleck and Bleck Architects LLC. Available online: http://bleckarchitects.com/2014/08/flywheellaunchedcoaster/ (accessed on 11 February 2017).

83. Williams Hybrid Power-Advanced Flywheel Energy Storage. Available online: http://www.esa-tec.eu/ space-technologies/for-space/williams-hybrid-power-advanced-flywheel-energy-storage/ (accessed on 11 February 2017).

84. Cotton, A. Audi R18 (2014). Racecar Engineering, 1 June 2014.

85. GKN Gyrodrive Flywheel Hybrid System. GKN Develops Electric Flywheel Hybrid System for Buses. Available online: http:/ /articles.sae.org/13905/ (accessed on 11 February 2017). 
86. Truong, L.V.; Wolff, F.J.; Dravid, N.V. Simulation Of Flywheel Electrical System For Aerospace Applications. In Proceedings of the 35th Intersociety Energy Conversion Engineering Conference and Exhibition, Las Vegas, NV, USA, 24-28 July 2000; Volume 1, pp. 601-608.

87. US Marine Corps Utilising Microgrid Energy Storage Project. Available online: http:/ /www.decentralizedenergy.com/articles/2015/09/us-marine-corp-utilising-microgrid-energy-storage-project.html (accessed on 1 February 2017).

88. Sanders, S.; Senesky, M.; He, M.; Chiao, E. Low-Cost Flywheel Energy Storage Demonstration; Energy Research and Development Division Final Project Report; Amber Kinetics, Inc.: Union City, CA, USA, 2015.

89. Gurumurthy, S.R.; Sharma, A.; Sarkar, S.; Agarwal, V. Apportioning and mitigation of losses in a Flywheel Energy Storage system. In Proceedings of the 4th IEEE International Symposium on Power Electronics for Distributed Generation Systems (PEDG), Rogers, AR, USA, 8-11 July 2013.

(c) 2017 by the authors. Licensee MDPI, Basel, Switzerland. This article is an open access article distributed under the terms and conditions of the Creative Commons Attribution (CC BY) license (http:/ / creativecommons.org/licenses/by/4.0/). 